\title{
The therapeutic relationship and change processes in child psychotherapy: a qualitative, longitudinal study of the views of children, parents and therapists
}

\author{
Lucía Núñez, ${ }^{1,2}$ Sofía Fernández, ${ }^{1}$ Nicolle Alamo, ${ }^{3}$ Nick Midgley, ${ }^{4,5}$ Claudia Capella, ${ }^{2}$ Mariane Krause ${ }^{1}$ \\ ${ }^{1}$ Psychology Department, Pontifical Catholic University of Chile, Santiago, Chile; ${ }^{2}$ Psychology Department, University of Chile, Santiago, \\ Chile; ${ }^{3}$ Social Work School, Pontifical Catholic University of \\ Chile, Santiago, Chile; ${ }^{4}$ Child Attachment and Psychological \\ Therapies Research Unit (ChAPTRe), Anna Freud National \\ Correspondence: Lucia Nuñez, University of Chile and Pontifical \\ Catholic University of Chile. \\ E-mail: luciabn@gmail.com \\ Centre for Children and Families, London, UK; ${ }^{5}$ Research \\ Department of Clinical, Educational and Health Psychology, \\ University College London (UCL), UK
}

Citation: Nuñez, L., Fernández, S., Alamo, N., Midgley, N., Capella, C., \& Krause, M. (2022). The therapeutic relationship and change processes in child psychotherapy: a qualitative, longitudinal study of the views of children, parents and therapists. Research in Psychotherapy: Psychopathology, Process and Outcome, 25(1), 103-117. doi: 10.4081/ripppo.2022.556

Acknowledgements: Mental Health Unit, San Joaquín Medical Center of the UC CHRISTUS Health Network, and the children, mothers and therapists who participated in this study.

Funding: this work was funded by the National Agency for Research and Development (ANID) / Scholarship Program / DOCTORADO BECA NACIONAL/ 2016-21160244, and the ANID Millennium Science Initiative /Millennium Institute for Research on Depression and Personality-MIDAP ICS13_005.

Contributions: LN and MK, conception and design of the study; LN, SF, NA, NM, CC, analysis and interpretation of data; LN, SF, NA, drafting the article; LN, SF, NA, NM, CC, MK, revising it critically for important intellectual content, final approval of the version to be published, agreement to be accountable for all aspects of the work.

Conflict of interest: the authors declare no potential conflict of interest.

Ethical approval and consent to participate: ethical approval for this study was granted from the Scientific Ethics Committee in Social Sciences, Arts and Humanities of the Pontificia Universidad Católica de Chile, Protocol ID: 180614006 (August 7, 2018). The study was also authorised by the Mental Health Unit, San Joaquín Medical Center of the UC CHRISTUS Health Network in compliance with Article 11 of Law 20120 of the Chilean Ministry of Health. The informed consent of parents and therapists and children's informed assent to participate were requested.

Availability of data and materials: interviews and drawings stored by the first author.

Received for publication: 18 June 2021.

Revision received: 28 January 2022.

Accepted for publication: 24 February 2022.

This work is licensed under a Creative Commons Attribution NonCommercial 4.0 License (CC BY-NC 4.0).

${ }^{\circ}$ Copyright: the Author(s), 2022

Licensee PAGEPress, Italy

Research in Psychotherapy:

Psychopathology, Process and Outcome 2022; 25:103-117

doi:10.4081/ripppo.2022.556

\section{ABSTRACT}

Through the perspectives of children, parents and therapists, this study explored the therapeutic relationship as a change facilitator in different moments of psychotherapy. The children, parents, and therapists $(\mathrm{N}=15)$ who formed part of five therapeutic treatments were studied using a qualitative, longitudinal design. Thirty semi-structured interviews were done; half at the beginning and half after four months of psychotherapy. Children's drawings were incorporated, and data were analysed through grounded theory methods and qualitative analysis guidelines for drawings. Participants identified several aspects of the therapeutic relationship as change facilitators. From the first encounters, the therapists' close and adaptable attitude promoted an improved motivation for psychotherapy and enhanced engagement among children and parents. Later in the process, a positive, child-centred and affective therapeutic relationship fostered the child's trust with the therapist as well as a positive relational experience, promoting associated changes in children and the development of socio-affective tools. Parents and therapists saw their own relationship as a change facilitator, as well as a broader understanding in parents of their children and an improved relationship with them. Parent's and child's changes helped each other. Specific and common aspects between participants' perspectives provided a richer understanding of the studied phenomena. This study supports the view that a positive therapeutic relationship facilitates early changes in the motivation of children and parents, and provides them with a healing, relational experience as it develops. A positive parent-therapist relationship is also key for changes to further progress.

Key words: Child psychotherapy; therapeutic relationship; change processes; children's drawings; qualitative methods.

\section{Introduction}

Studies on the effectiveness of psychotherapy - measured through the reduction of symptoms - have consistently concluded that child psychotherapy is effective (Fonagy et al., 2015; Weisz et al., 2013). However, when considering changes that are meaningful to patients and therapists, therapeutic change is not just about the improvement of symp- 
toms (Gómez \& Roussos, 2012; Krause, 2005). The experience of change of those who participate in psychotherapy has been conceptualised as 'subjective change', which implies a process of transformation of the subjective perspective of how the patients regard themselves and their problems, their environment, and their relationship with it (Gonçalves, Matos, \& Santos, 2009; Krause et al., 2006). This standpoint supports the growing appreciation for clients' perspectives on therapeutic change, balancing the emphasis on quantitative outcomes (Elliott, 2008). In this sense, qualitative methods seem to adjust better to the task of reaching a deeper understanding of psychotherapy participants' subjective experiences (Altimir et al., 2017).

The therapeutic relationship has played a central role in theories addressing the therapeutic process and has been signalled as the common factor that best explains changes in adults (Horvath, Del Re, Flükiger, \& Symonds, 2011) and in children and adolescents (Hawley \& Weisz, 2005; Karver, Monahan, De Nadai, \& Shirk, 2018). The therapeutic relationship has been defined as the feelings and attitudes that therapists and patients experience for each other and how they are expressed (Gelso, 2014). The interplay between the technical and relational aspects of therapy has been noted, as they show mutual influence during the process (Gelso, 2019).

In contrast with the abundant research on adult psychotherapy, the therapeutic relationship in child psychotherapy has been less studied (Midgley, Hayes, \& Cooper, 2017). In child psychotherapy, this relationship has been usually reviewed through instruments based on Bordin's (1979) therapeutic alliance model (Wilmots, Midgley, Thackeray, Reynolds, \& Loades, 2019), and it has been examined mainly from the reports of therapists and parents (Noyce \& Simpson, 2018).

The therapeutic alliance model comprises the patient and therapist bond, collaboration on goals and tasks (Bordin, 1979). It has proved small but significant positive correlations with outcomes in child psychotherapy (Kazdin, Whitley, \& Marciano, 2006; Shirk \& Karver, 2011). A positive therapeutic alliance has been associated with symptomatic improvements in children (Hawley \& Weisz, 2005; Liber et al., 2010) and positive outcomes in treating different disorders (Karver et al., 2018). Moreover, further therapeutic changes are observed as this alliance grows deeper (Kazdin \& Durbin, 2012). Regarding the therapeutic process, a positive relationship between alliance and treatment adherence has been reported in adults from the initial phase of therapy (Principe, Marci, Glick, \& Ablon, 2006). In child psychotherapy, mixed results are observed; one study showed that the early alliance with children and adolescents had no predictive value on the premature termination of therapy (Abrisami \& Warren, 2013). In contrast, another study reported that a positive alliance with children and parents was associated with higher adherence and completion of therapy (Hawley \& Weisz, 2005).
Considering these previous findings, three possible conclusions concerning child psychotherapy practice stand out, all of which require further investigation. First, establishing the child-therapist relationship may have a slower evolution than this process in adults (Shirk \& Karver, 2003). Considering that collaboration is not as clear as with adult patients, forming a therapeutic alliance with children can be a complex process. Elementary school-aged children may be reluctant to engage in psychotherapy as they may not fully understand why they have been brought to treatment and do not always agree with the adults about the therapeutic goals (Shirk \& Karver, 2011). Despite these findings of possible initial difficulties in forming the therapeutic relationship, the evolution of the therapeutic relationship and its role in change processes in different moments in child psychotherapy has been scarcely studied.

Second, there are multiple levels of relationships in child psychotherapy, including those between the child and the therapist and between the parent or caregiver and the therapist (Shirk \& Karver, 2011; Karver et al., 2018). These relationships work in a triadic way, as they dynamically influence each other (Gvion \& Bar, 2014) and imply that parents also play a fundamental part in the child's therapeutic change (Karver et al., 2018). It has been reported that the poor motivation of parents to start psychotherapy for their children, their expectations of not being involved in their treatment and their limited ability to think about feelings may be related to dropout rates in psychotherapy (Midgley $\&$ Navridi, 2007). Likewise, the parent-therapist relationship is associated with the commitment and the extra-session support of parents, which affects the child therapeutic change (Marker, Comer, Abramova, \& Kendall, 2013). The parent-therapist alliance is positively associated with better parental skills and family interactions (Shirk \& Karver, 2011). When this positive alliance is combined with high parental commitment with the psychotherapy, it also exerts a positive influence on the quality of the therapeutic alliance with the child (Campbell \& Simmonds, 2011; Kazdin et al., 2006). The development of strong therapeutic relationships with children and their families - through providing a stable, supportive, and accepting context -, may facilitate the engagement to therapy and decrease the resistance to treatment (Karver et al., 2018). However, few studies address the child-therapist and parent-therapist relationship as a triadic setting to deepen the mutual influence in the change process.

Thirdly, the views of different participants regarding the therapeutic relationship should also be considered. Some studies have found that children, parents and therapists tend to converge on a positive valuation of the therapeutic relationship (Zorzella, Rependa, \& Muller, 2017), while others have observed differences between their reports (Accurso \& Garland, 2015; Kazdin et al., 2006; Zandberg, Skriner, \& Chu, 2015). Children and parents report a higher valuation of the alliance than therapists 
(Accurso \& Garland, 2015; Zandberg et al., 2015), while the latter are more aware of alliance deterioration (Accurso \& Garland, 2015). Children's positive perceptions about the alliance have been more associated with good outcomes than their parents' perceptions (Green, 2006). These mixed findings emphasise the need to explore further the convergences and differences between the perspectives of children, parents and therapists and the central aspects drawn from each viewpoint.

The importance of including children's views, as they deliver valuable information regarding their therapies, has been emphasised in the literature (Carlberg, Thoren, Billstrom, \& Odhammar, 2009; Midgley, 2004). Innovative methodologies such as play and drawing have been used to favour the expression of children in a developmentally sensitive way; this approach has enabled researchers to gain new perspectives (Alamo, 2019; Capella et al., 2015; Carlberg et al., 2009). Many children identify initial problems, and although their expectations towards therapy may be unclear or not recalled, their main concern can be not to get bored (Carroll, 2002). Children tend to report positive assessments of their psychotherapy (Capella et al., 2016) and point out that spending time with their therapist is what they like the most about therapy (Carlberg et al., 2009). Children report achieving a deeper understanding of their problems, underlining that the therapist provided them with emotional support and listened to them (Capella et al., 2016).

The previous arguments support the therapeutic relationship with children and their parents as a central factor in the therapeutic change process. However, less is known regarding how it helps in different phases of psychotherapy from the perspective of children, parents and therapists. This study explores the child-therapist and parent-therapist relationship as a change facilitator at two different moments of the process from children's, their parents', and therapists' perspectives. The main convergences and divergences among their perspectives are examined, emphasising the key elements of each viewpoint. Considering that this study focuses on school-age children, that is, children between 6 and 11 years old (Pappalia \& Martorell, 2015), an age-sensitive methodology (drawings) was used.

\section{Methods}

\section{Settings}

This study was conducted in an outpatient university generalist mental health service in Santiago de Chile. It involved children referred to psychotherapy in this service, their parents, and therapists.

\section{Design}

A qualitative longitudinal study that considered two different moments of the therapeutic process was devel- oped. A multi-perspective approach was employed (Levitt, 2021) to explore the experiences of children, their parents, and therapists.

\section{Participants}

This study focused on school-age children who attended weekly psychotherapy, with at least one of their parents actively involved in the process. Exclusion criteria were impairing psychiatric disorders in the child or the caregiver or dropout from psychotherapy. Five cases were selected for this study, considering that in psychotherapeutic process research the focus is on depth in the analysis, including different variables and moments of evaluation, being common to work with small sample sizes (Krause \& Altimir, 2016). Each case comprised the child, their mother and therapist, creating a total of fifteen participants who took part in psychotherapy for four months. Each participant was interviewed at two different time points, leading to thirty interviews. The sampling strategy was purposive and was based on maximal variation in terms of the sex and age of children, consulting reason and theoretical framework of the therapist. The intentional diversity between participants allowed a more exhaustive exploration of differential experiences within the studied group (Flick, 2018).

Three girls and two boys between seven and nine years old ( $M=8.2$ years) participated in this study; they were referred to mental health care for various reasons, including attention-deficit disorder, emotional dysregulation, anxiety, depressive and somatic symptoms. They were given the following pseudonyms: Dawn, Eva, Zane, Mia, and Vince. Five mothers between twenty-nine and thirty-four years old ( $\mathrm{M}=32.4$ years) actively participated in their children's therapy. The invitation to participate was extended to both parents; however, fathers did not participate in this study as they were not present at the moment of the interviews. This situation reflected their low participation in the therapeutic process or difficulties accompanying their children to sessions. The four female and one male therapist who participated represented diverse theoretical frameworks (systemic, psychoanalytic, cognitive-constructivist and integrative) but were more homogenous in terms of age, representing a young group ( $M=26$ years, $S D=5.2$ ) with few years of clinical experience ( $M=2.8$ years, $S D=4.6)$. Three therapists were in training, a fourth was initiating her career, and a fifth had eleven years of practice. Therapies were open-ended, and interventions included individual sessions with the child and their parents and family sessions. Directive and nondirective play, art and narrative techniques were offered. Participants' characteristics are detailed in Table 1.

\section{Procedure}

Participants were contacted at the beginning of psychotherapy in the mental health service. After the first or 
second therapy session, research team members conducted separate parallel interviews with children, parents and therapists at the centre. After four months of therapy $(\mathrm{M}=16.4$ sessions), participants were re-interviewed. Children's interviews included drawings to enhance their narratives and were led by a child psychotherapist who was not part of the treatment team. Interviews were audiorecorded and transcribed using the Mergenthaler Norms (Mergenthaler \& Gril, 1996).

\section{Data collection}

\section{Semi-structured interviews}

The interview protocol was developed for children; scripts for parents and therapists were adapted from this protocol. The script was oriented by three dimensions: i) expectations, consultation reason, and initial motivation towards psychotherapy; ii) experience of the therapeutic relationship with children and parents; iii) experience of psychotherapeutic change in children and parents. Based on these dimensions, an interview guideline was created, which began with 'ice-breaking' questions, and then a broad question: 'What is it like to come to the therapy? I'd like to know whatever you want to tell me about it'. Then, specific questions were asked if their content did not emerge in the free narrative, for example: Do you think psychotherapy will help you? How is your therapist? How do you get along with him/her? Did something change in you, in others? Why do you think it changed? The same interview script was used in the initial moment and after four months of therapy.

\section{Drawings}

Children's drawings took place in each interview and were in continuous dialogue with the interview topic guide. Interviewers engaged with the children about their drawings and asked non-leading questions about what they drew.

The two drawings included in the first interview were 'My psychologist and me' (Núñez et al., 2021) and 'How am I at the beginning of therapy/How I want to be at the end of therapy', a variation of the drawing 'Before/after therapy' (Capella et al., 2015). For the first drawing, children were asked to draw themselves with their therapist during therapy, and for the second, children were asked to draw themselves how they were at the beginning of therapy and how they would like to be when it ends. Colouring pencils and a sheet of letter-sized paper were provided, which for the second drawing had a vertical line in the middle, generating side-by-side illustrations. Two drawings were requested in the same terms as in the initial interview in the second interview. They included 'My psychologist and me' (Nuñez et al., 2021) and 'How was I before therapy/How am I now' (Capella Gutiérrez, Rodríguez, \& Gómez, 2018). For this last drawing, children were asked to draw how they felt and were before starting therapy and in the current moment.

\section{Data analysis}

Grounded theory methods (Corbin \& Strauss, 2008) were employed to analyse data, as it is a discovery-driven naturalistic method aimed to capture the complexity of social interactions as they take place. Data analysis pursued a comprehensive description of the phenomenon through the participants' subjective perspectives (Altimir et al., 2017) and the construction of meanings (Levitt, 2021).

Open coding was based on a concept-indicator model that consisted of labelling emerging concepts related to individual indicators, categorised considering theoretical and contextual information (Corbin \& Strauss, 2008; Titscher Meyer, Wodak, \& Vetter, 2000). Through an iterative analysis process, emerging concepts were sorted in a hierarchical organisation. How concepts and categories develop and relate was registered through coding memos. ATLAS.TIv8 software supported open coding. Subsequently, axial coding was done to map relationships among concepts and categories.

An intersubjective triangulation strategy was employed to decrease coder bias, safeguard validation, and enrich the data analysis, allowing several views to be considered (Altimir Capella, Núñez, Abarzúa, \& Krause, 2017). Six coders participated in different phases of identifying categories, comparing findings, and pursuing agreement (Flick, 2018).

After the initial analysis of drawings as part of the interview with children, these were further explored through qualitative analysis guidelines for therapeutic process-outcome drawings (Alamo, 2019; Nuñez et al., 2021), focusing on the content analysis step, which explores the

Table 1. Participants characteristics.

\begin{tabular}{|c|c|c|c|c|c|c|c|c|c|}
\hline \multicolumn{4}{|l|}{ Child } & \multicolumn{3}{|c|}{ Parent } & \multicolumn{3}{|c|}{ Therapist } \\
\hline Case pseudonym & Sex & Age & Consulting reason & Age & Kinship & Sex & Age & Theoretical approach & Practice (years) \\
\hline Dawn & $\mathrm{F}$ & 7 & ADD/emotional dysregulation & 32 & Mother & $\mathrm{F}$ & 35 & Cognitive- constructivist & 11 \\
\hline Eva & $\mathrm{F}$ & 9 & Anxiety/depressive symptoms & 29 & Mother & $\mathrm{F}$ & 23 & Systemic & 0.5 \\
\hline Zane & M & 7 & Somatization/emotional dysregulation & 34 & Mother & $\mathrm{F}$ & 23 & Integrative & 0.5 \\
\hline Mia & $\mathrm{F}$ & 9 & Anxiety/social phobia & 33 & Mother & M & 23 & Psychoanalytic & 0.5 \\
\hline Vince & M & 9 & Depressive symptoms/Memory issues & 34 & Mother & $\mathrm{F}$ & 26 & Systemic & 1.5 \\
\hline
\end{tabular}


following elements: i) Central theme; ii) Central figures; iii) Environment; iv) Interaction between elements; v) Use of colour as an expression tool.

The initial data analysis and the further analysis of drawings were integrated through methodological triangulation (Flick, 2018). The perspectives of children, parents and therapists were treated separately; then, they were integrated when convergences were observed and differentiated when not. Findings from both time points were described and compared, entailing a descriptive and relational process analysis (Corbin \& Strauss, 2008).

\section{Ethical considerations}

Ethical approval for this study was granted from the Scientific Ethics Committee in Social Sciences, Arts and Humanities of the Pontificia Universidad Católica de Chile, Protocol ID180614006 (August 7, 2018).

\section{Results}

Participants described a positive therapeutic experience and identified several interrelated changes favoured by a positive child-therapist relationship, at the beginning and after four months of psychotherapy. Parents and therapists also mentioned their relationship as a change facilitator, noting that changes in children and parents facilitated each other.

After open coding, five core dimensions regarding the change processes facilitated by the therapeutic relationship were developed, and their relationships were organised through axial coding (see Figure 1). The core dimensions are: i) beginning of therapy: understanding the problem and disposition towards psychotherapy; ii) the first encounters with the therapist and initial changes; iii) change facilitators associated with the development of the child-therapist relationship; iv) change facilitators associated with the parent-therapist relationship; v) changes in children, parents, and their relationship after four months of therapy.

\section{Beginning of therapy: 'I look black and grey inside'}

The parents spontaneously decided to start psychotherapy or followed the referral made by another professional. The initial consulting reason identified by participants was the child's emotional distress. Children emphasised feeling sad or upset about their problems, and some added having difficulties and feeling isolated in peer relationships. These emotions appeared in the drawings of themselves at the beginning of therapy, in which troubled faces were observed. Scarce or no colour was utilised, and some children obscured their figure or added environmental elements to represent their emotional distress. These aspects appear in Vince's drawing (Figure 2), about which he said:

'I drew myself with a grey background because of the sadness and loneliness I felt (...). I look black and grey inside because of all the pain I had at the other school' (Vince).

It was observed in the children's drawings that their self-concept and difficulties were mingled at the begin-

Beginning of therapy

Initial understanding of the child and the problem; positive/negative expectations and motivation/reticence in the child

First positive encounters between child and therapist enable an improved motivation in the child and confidence in parents

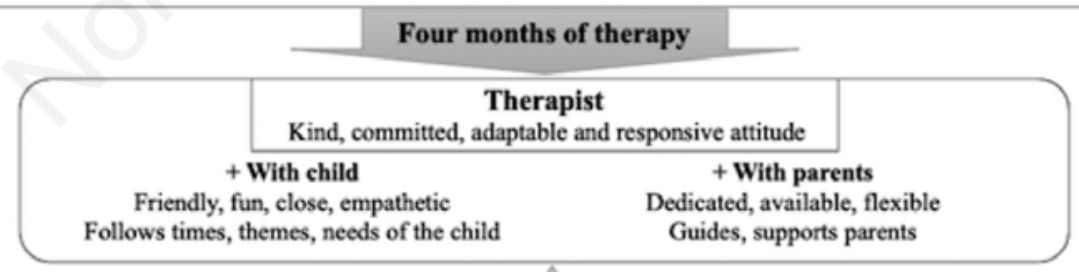

Therapeutic relationship with child Child-centred, close, free, joyful, playful relationship Trust is built: child opens personal and conflictive issues

Kind, good disposition, responsive. Enjoys playing, doing art and talking with therapists. Feels helped, trusts and likes their therapist.

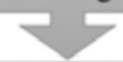

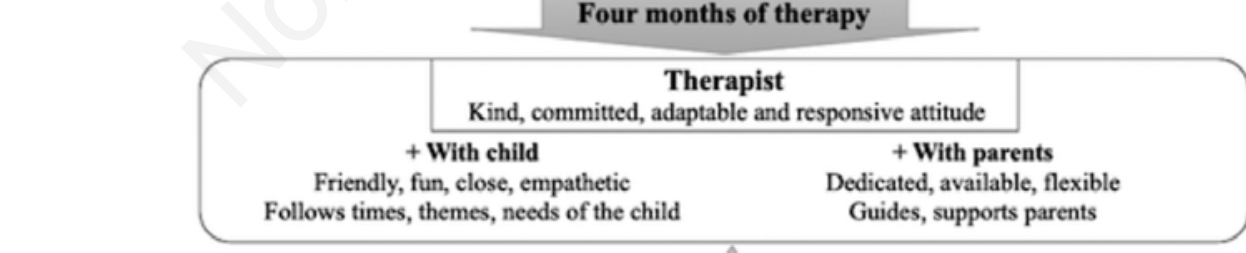

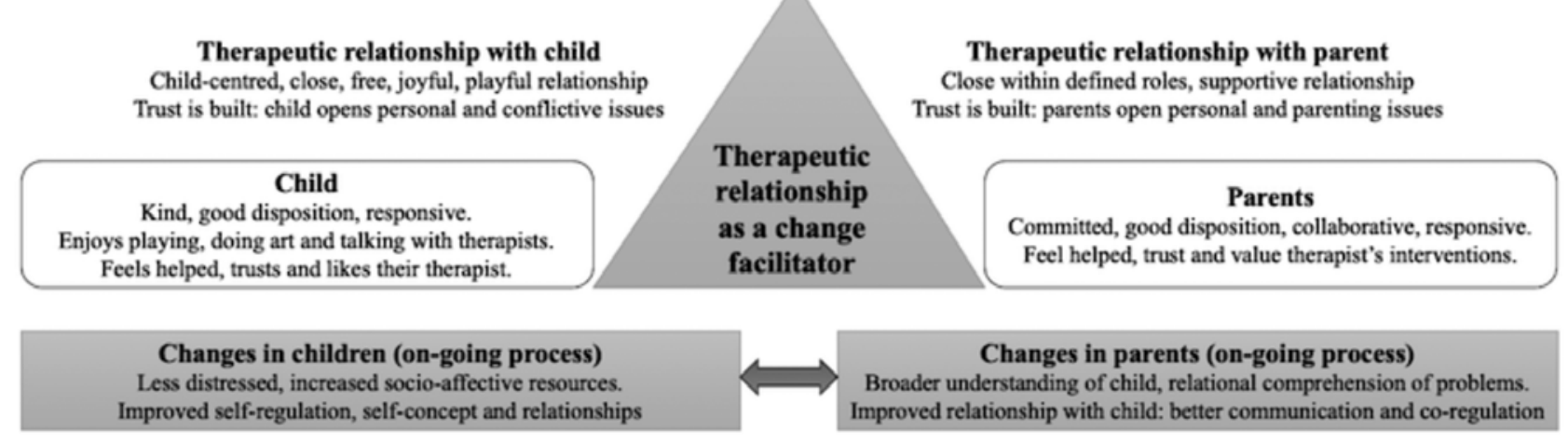

Figure 1. Therapeutic relationship as a change facilitator. 
ning of the therapy; children came to the first session feeling bad about themselves and self-conscious in their relationships with others.

Some children and parents added a relational understanding of their problems, feeling responsible and distressed for generating discomfort in the other, as Eva held:

'I've been too sad, and I cry for nothing. My mom stresses because she doesn't know what's wrong with me (...) she stresses out very quickly' (Eva).

From the parents' perspective, things worked in the other direction, as one mother stated:

'She started with these episodes, first, because I started studying and, second, because I have panic attacks (...) so, I think that seeing me so low also affected her' (Mia's mother).

Parents added feeling overwhelmed by their child's problems, seeking help from the therapist to deal with their child and better understand them.

Generally, participants had positive initial expectations of the therapeutic process. Nevertheless, some children expressed negative expectations of the therapist or the effectiveness and purpose of therapy, leading to reticence and low motivation. Dawn expressed in this regard:

'I didn't want to come (...) because I didn't know... I thought she [therapist] was going to be grouchy' (Dawn).

In these cases, parents and therapists related the child's lack of motivation to tiredness and a negative mood due to the evening schedule of the session more than to the reasons raised by the children, evidencing discrepancies between their views.

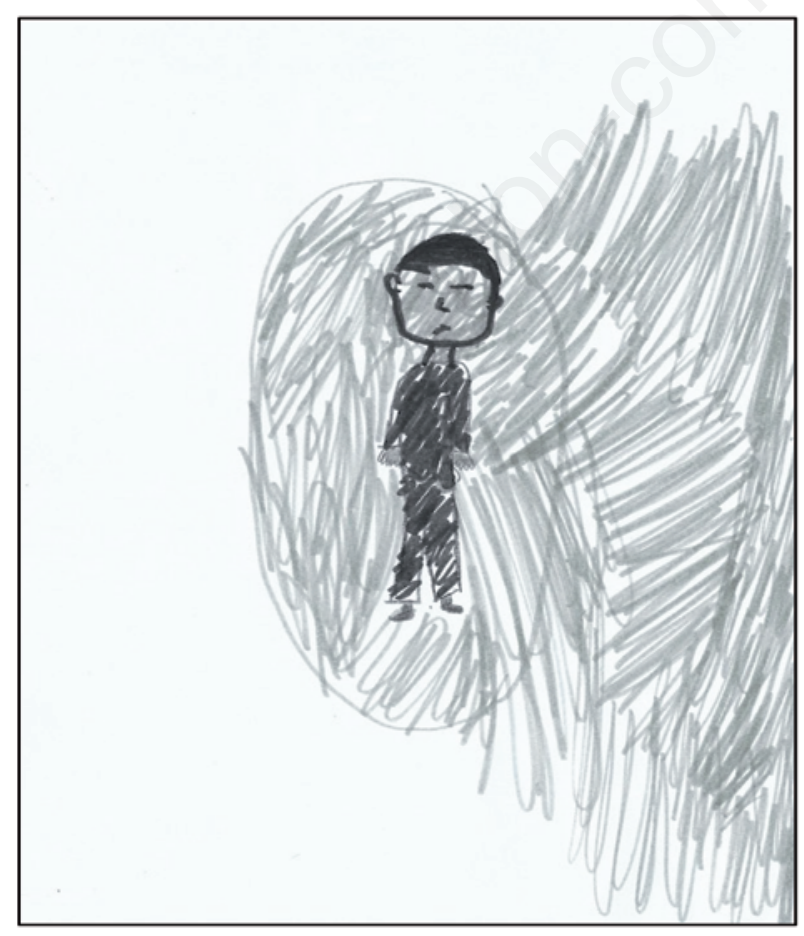

Figure 2. 'How was I before therapy' (Vince's first drawing).

\section{The first positive encounter with the therapist and initial changes: 'she came really reluctantly, and at the end, she didn't want to leave'}

The initial attitude of children with the therapist reflected their initial motivation; it was described as positive by some participants and as rejecting by others, as one mother explained:

'When we entered the interview with him, she was serious, very apathetic, like upset because she didn't feel like coming' (Mia's mother).

Despite this variability in the children's attitudes, children and parents underlined that the therapist was friendly, nice, and kind to the child, which they positively valued.

After the first sessions, an improved disposition in the child and greater collaboration with the therapist was reported by participants. According to their perspectives, this change derived from the good initial connection between child and therapist, as one therapist described:

'The session had this development because she came very reluctantly, and at the end, she didn't want to leave because we were talking, we were laughing. (...) it was a lovely session, and now she's super motivated to come back to the next one' (Mia's therapist).

Parents and therapists also pointed out that the child's initial mood improved after the first sessions, feeling happier and less troubled. Parents mentioned feeling calmer and more confident after observing how the therapist managed to establish a positive relationship with their child.

Children emphasised feeling good and happy in these first encounters with the therapist; parents observed that their child felt comfortable and free, and some therapists mentioned that the child had fun and a good time. This positive relationship was represented in the children's drawings; when asked to draw the therapy situation at the first interview, the central figures had happy faces, and positive feelings were expressed. In these drawings, the interaction between figures focused on the therapist's action, who asked questions or spoke. The consulting room setting was emphasised through the furniture, materials, walls and door. It is possible to observe these elements in the drawings of Eva (Figure 3) and Zane (Figure 4).

Boundaries and concrete elements of the consulting room in children's drawings seem to organise and sustain the interaction in this first moment of the therapeutic relationship.

\section{Change facilitators associated with the development of the child-therapist relationship}

After four months of therapy, participants expressed that the therapeutic relationship was a fundamental change facilitator. The attitudes and disposition of the child and therapist enabled a positive evolution of the therapeutic relationship, particularly in terms of trust and openness in the child. It was noted that the therapist's interventions and attitudes merged from the point of view 
of children and parents, while therapists made a distinction between them.

\section{Attitudes and disposition of child and therapist that facilitated a positive development of the therapeutic relationship: 'she's funny and nice'}

Children and parents again highlighted the therapist's nice, kind and friendly attitude towards the child as facilitators of the therapeutic relationship. Parents added that the therapist was caring, close and warm, and children said that the therapist was fun and cheerful. Children liked the way their therapist was and felt good with them, as Vince pointed out:

'She's funny and nice. (I: How do you feel with her?) I feel good, I feel like reassured (...) (I: What do you like most about her?) That she lets me draw a lot' (Vince).

Participants also emphasised the therapist's flexibility to adapt to the needs of children and give them freedom of expression, meaning that children felt comfortable in psychotherapy, as one therapist describes:

Figure 3. 'My psychologist and me' (Eva's first drawing).

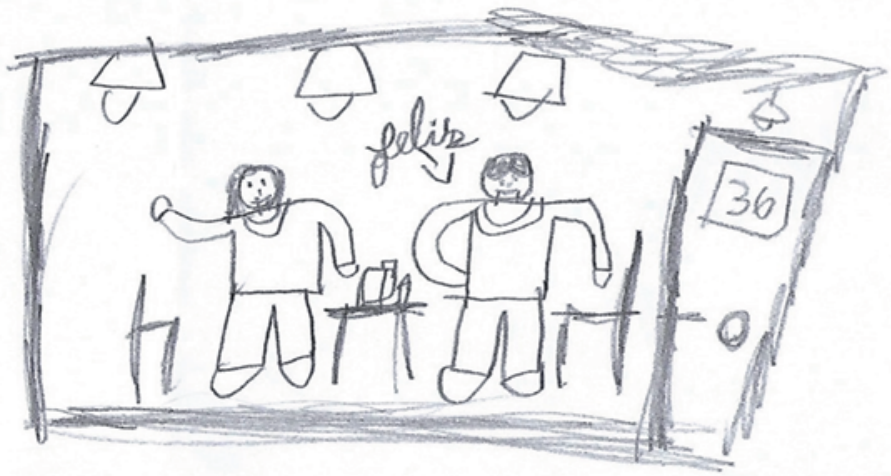

Figure 4. 'My psychologist and me' (Zane's first drawing). 
'I take the issue of bonding with the patient based on their needs and way of being very seriously (...) if I'd already planned some objectives for the session, I always adapted to the spontaneous contents that Mia could bring' (Mia's therapist).

Therapists mentioned focusing on the child's interests, playing and doing things together, as facilitators of the therapeutic relationship. The activities offered by the therapist were appealing for the children; they positively valued play and art, and some of them appreciated talking with their therapist. For therapists, the use of play and art went beyond being relational facilitators; they were conceived as change facilitators by supporting an empowered role in the child, allowing the therapist's access to the inner feeling and conflicts of the child and focus on them.

Children were described in this relationship as kind, friendly, responsive, and with a good disposition towards the therapist, which was considered a therapeutic relationship facilitator.

\section{The positive evolution of the therapeutic relationship: 'she opened little by little'}

All children mentioned feeling good and happy with their therapist at this point in the process. Changes were observed when comparing the children's drawings of the therapeutic relationship at the beginning and after four months of therapy. At the second time point, the central figures were happy as in the first drawings, but their in- teraction was more active and playful; there was greater use of colour associated with the expression of affection. The emphasis on the consulting room disappeared. These changes can be seen in the drawings of Zane; in his first drawing, he emphasised the consulting room (Figure 4), but in the second one, he just represented himself and his therapist as 'very happy chatting' (Figure 5). This change was also observed in the drawing of Dawn (Figure 6), who in her initial drawing detailed the consulting room environment and at the second moment emphasised the playful interaction with her therapist, noting that they felt good while having fun.

In the children's second drawings, the focus was on the two people in the room and not on the material elements of the consulting setting, implying that the therapeutic relationship evolved towards a freer encounter, with greater symmetry in terms of roles and actions and centred on positive and playful interaction. This aspect concurs with the parent's report of a close, friendship-like relationship between child and therapist.

For participants, a central aspect that arose from this relationship was trust. Parents and therapists saw trust as an expression of positive affection between child and therapist, and this affection would be eased by having fun together. One therapist described the girl's process:

'We got to know each other, and our interaction improved. She started to tell a little of her story, to talk more about her family (...) as the sessions progressed, she also

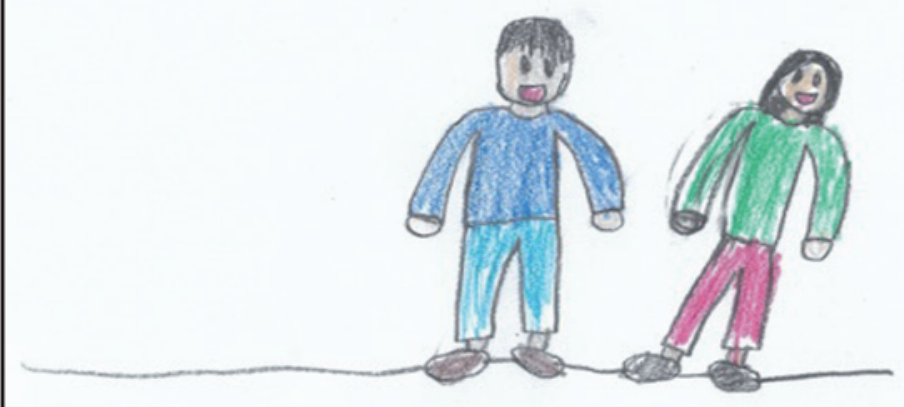

Figure 5. 'My Psychologist and me' (Zane's second drawing). 
brought things, showed me things, told me things (...) then she was happy (...) being able to laugh in the session, constantly; she advanced towards a more trustful space' (Mia's therapist).

The increased emotional connection between patient and therapist was also associated with the progressive growth of the child's collaboration and involvement in the process. In this regard, one therapist noted:

'There was a cooperative atmosphere that strengthened (...) until I finally saw her smile, and that, for me, was the best. I felt like she wanted to come. She opened little by little; we went from 'I don't know' to more words and actions that concerned her' (Eva's therapist).

Some parents and therapists emphasised that this trust and affection was deep and special and generated confidence that the child would not have with others, as one mother described:

'She adores her (...) like she gave herself to her and talks, she lets herself go with her, it's something that she doesn't do. With me, she doesn't talk, she's a girl who doesn't talk about her stuff, and with [therapist's name] she opened (...)' (Eva's mother).

Opening relevant personal topics with the therapist was identified by therapists and parents as a facilitator of change because it allowed addressing these issues.

Children and therapists noted that therapists felt good and happy with the child, enjoying their company and the possibility of helping them. At the same time, therapists felt fond of the child but sad for the difficulties they faced. This emotional involvement generated mixed feelings in some young therapists, as expressed by one:

'I want to adopt her (laughs) like I... involved a lot of my feelings, and that's a stumbling stone on the affective side, on my part. I mean, I understand that I'm young, I don't have much experience (...), but personally, I really like this little girl (...) it's been a very good experience, very difficult too (...). However, it gives me great hope to see the small and great steps we have achieved along the way' (Eva's therapist).

As noted in the previous quote, the emotional involvement of the therapist also implied a high level of commitment towards the child's progress, and this commitment was viewed as a relationship facilitator by participants.

\section{Change process facilitators associated with the parent-therapist relationship}

Parents and therapists emphasised the direct work of the therapist with parents, the collaboration of parents and a positive therapeutic relationship between them as significant facilitators of change for the child and the parents. Children reported that their parents and the therapist got along well, but they did not say much about this relationship as a change facilitator.

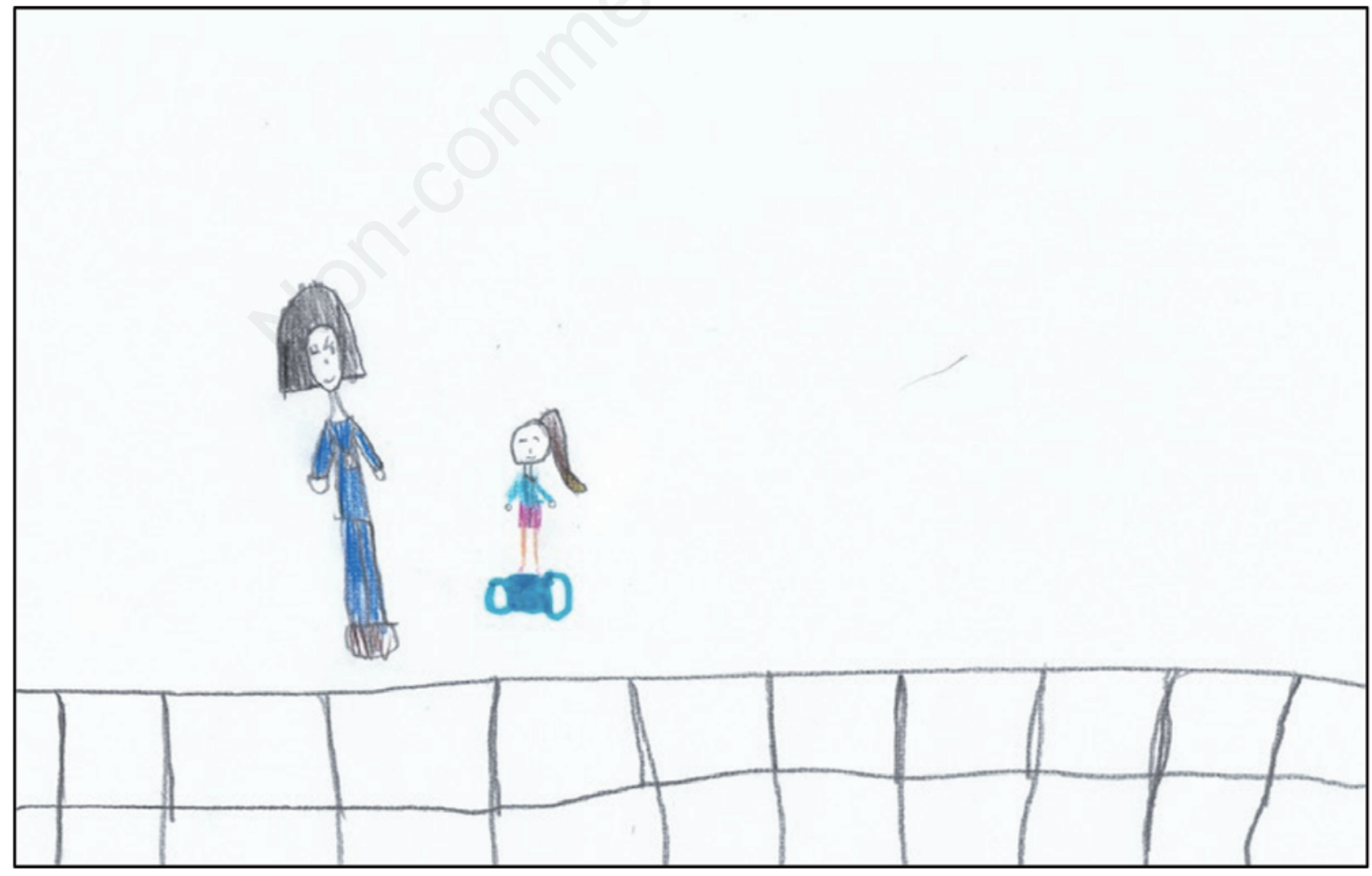

Figure 6. 'My Psychologist and me' (Dawn's second drawing). 
Attitudes and actions of parents and therapist:

'She took time to listen to us'

Individual and family sessions with their child's therapist were positively valued by parents, who highlighted the therapist's help to understand better their child's psychological issues and the specific strategies to improve the parent-child relationship. Therapists and parents noted that parents were receptive to these interventions, which facilitated their changes.

Some therapists also highlighted handling parents' personal issues that arose in their sessions. This point strengthened their relationship through an improved parent's disposition towards the therapist. One therapist referred to this change:

'After she [mother] opened up her abuse experience, and I was able to contain her, to my surprise, she changed (...) she went from being rough to a bit warmer' (Eva's therapist).

Therefore, the therapist's work with parents was noted as a change facilitator at two levels: parental role and strengthening the parent-therapist relationship.

Parents pointed out the commitment and interest of the therapist in their experiences as a facilitator for positive therapy outcomes, as well as the therapists' kind, available and responsive attitude with them. They perceived that the therapist tried to incorporate them in the process, adjusting to the needs of both child and parents, as one mother described the therapist:

'I feel she is committed with the case. She is very kind, affectionate, very empathetic with him, which also helped him. She talked to us [parents] as well; she took the time to listen to us (...) made an effort so both of us could go to parents' sessions' (Vince's mother).

Parents' commitment, concern, collaboration, and willingness to change was also highlighted by parents and therapists as change facilitators for the child and the family.

The therapeutic relationship with parents: 'If there is someone who doesn't get along in the working team, no, the work itself doesn't function'

The previously described features led to the construction of a positive therapeutic relationship between parents and therapists. Parents described this relationship as close but professional, reliable, and supportive, as one mother detailed:

'It's like close, but within a practitioner-patient relationship (...) like respecting those boundaries. But good, there is like a good reception. I feel her welcoming attitude, and I feel like the trust to tell her 'this happened, this other thing happened' (Zane's mother).

Parents and therapists stated that a good relationship between them was a significant facilitator of the therapeutic process, as it promoted the receptivity to the therapist's interventions.

Parents viewed psychotherapy as teamwork between the therapist, the child and them. A mother reflected on how a good therapeutic relationship affected the girl's therapy:

Figure 7. 'How I was before therapy/ I am now' (Vince's second drawing). 
'In a good way, since we are all working with her and if there is someone who doesn't get along in the working team, the work itself doesn't function' (Eva's mother).

A positive parent-therapist relationship, plus their commitment to the child's process and joint work, were described as facilitators of changes in children and parents.

Changes in children, parents, and their relationship after four months of therapy: 'my therapist helped me solve my problems and not feel so lonely'

Children mentioned feeling better, happier, and more relieved about the initial emotional distress that had brought them to therapy. These changes were observed in the drawings of themselves, which were more colourful, dynamic and had other people in them, compared to the drawings at the beginning of therapy. These changes may be noted in Vince's drawing (Figure 7), who said:

'[Before] Me, sad and forgotten in forgetfulness (...) I'm lonely (...) [I: And now?] I'm happy because I can play with my sister and I'm not so worried (...) (I: Why do you think it changes?) Because my therapist helped me to solve my problems and not feel so lonely' (Vince).

Changes observed in children's drawings pointed to changes in their self-concept, which became more positive and less burdened by difficulties than before psychotherapy. Parents and therapists also mentioned that children were more self-confident at this point. It is noteworthy that for children and parents, the changes in children were facilitated by the therapist's help.

Participants underlined a higher level of emotional regulation and development of socio-emotional skills in the child, related to a greater comprehension of internal states. These changes facilitated children's interpersonal changes, as improved relationships, greater interest in others, and enhanced social skills.

Parents and therapists positively valued these changes, as they enabled a more suitable response on their behalf. Parents also perceived that the changes in the child and themselves appeared together, in terms of greater mutual regulation, as one mother said:

'He reached a point where he threw a tantrum, cried, calmed down, cried again and then apologised (...). Not now, we talk, he explains what's happening to him, what's wrong or bothered him (...) it's a huge change (...). I feel calmer, more confident on how to approach the issues with him (...) and it's because he's also calmer' (Zane's mother).

An expanded comprehension in parents of their child's problem enabled a better disposition towards the child and improved the parent-child relationship. Therapists highlighted parents' enhanced listening and reflective ability and their greater support to the child.

Meaningful changes in children and parents were described at this extent of therapy. However, for some parents and therapists, more profound changes in the children were not felt to have been fully achieved and would require continuing therapy, as one mother stated:
'The core of the problem is still there, but the little rays that used to come out, which also affected him, have improved. The therapy has helped him, but he has been in treatment for a short time, and we have to continue to improve the core of the problem' (Vince's mother).

Some therapists emphasised parents' unfulfilled changes and considered that the change process in parents was slower than in the child. One therapist reflected:

'I feel that progress has been made in Dawn's behavioural regulation and that the mother manages to make more emotional attributions of Dawn's behaviour (...), but there is still this complaint in the mother that Dawn is 'difficult', that she has behavioural problems (...) I think that is where the challenge still lies' (Dawn's therapist).

Although for participants, not all the changes were fully reached after four months of therapy, the changes achieved would already have a positive impact on the child's future.

\section{Discussion}

In this study, a positive therapeutic relationship was seen as a facilitator of change in early and more advanced phases of psychotherapy. In the initial encounters, the therapeutic relationship favoured changes in three ways: first, by improving children's disposition towards therapy by handling their initial reticence. This study reinforces the importance of the first interactions between young patients and therapists (Fernández, Pérez, \& Krause, 2016; Shirk, \& Karver, 2003) and the therapist's ability to handle interpersonally challenging encounters with patients (Anderson Ogles, Patterson, Lambert, \& Vermeersch, 2009). Second, through supporting intrapersonal changes in children, as they felt better after a positive interaction with the therapist thus, the relationship became therapeutic by itself. And third, by favouring parent's confidence towards the therapist due to his or her ability to overcome the initial challenges set by the child.

The initial reticence observed in some children in this study towards psychotherapy has been reported in similar terms (Nuñez et al., 2021; Shirk \& Karver, 2011). However, this study explored further the reasons for this reluctance in children. While parents and therapists provided practical explanations related to the children's tiredness, children referred to negative expectations regarding the utility of psychotherapy and therapists' personal features.

The child-therapist and the parent-therapist relationship evolved positively in all treatments in this study, but in different terms. The therapeutic relationship with the child gradually strengthened in terms of affection and relational symmetry from the perspective of children and parents. This description resembles the concept of the real relationship (Gelso, 2019) and supports the discussion addressed by Gelso \& Kline (2019) of its relevance in psychotherapy. The real relationship is a person-to-person bond that grows from the emotional experience of patient 
and therapist of enjoying, appreciating and liking each other. It is different from the working bond described as a component of the therapeutic alliance (Gelso \& Kline, 2019). In this study, the evolution of the therapeutic relationship in child psychotherapy underlined the importance of the person-to-person bond for children and parents.

The parent-therapist relationship preserved a clearer asymmetry of roles during the processes studied than the therapeutic relationship with children due to the collaborative disposition in parents and their recognition of the professional function of the therapist (Altimir et al., 2017). The parent-therapist relationship came closer to the therapeutic alliance construct observed in adult psychotherapy, representing a 'teamwork relationship'.

In a more advanced phase, the therapeutic relationship with children and parents was also considered a change facilitator by children, parents and therapists, but at a deeper level than at the beginning of psychotherapy. In addition, more specific emphasis was observed between their viewpoints regarding this time point. Children felt good and happy in the therapeutic relationship, which functioned as an emotional motivator to engage in the process and build a meaningful relationship with the therapist. This positive experience with the therapist seemed to be very important considering that children reported feeling troubled in other relationships; it provided a valuable and healing relational experience for children. Children felt they changed due to the help of their therapist. Regarding parents, they highlighted children felt free and accepted by the therapist. Both parents and therapist emphasised that this positive therapeutic relationship enabled the construction of trust in the child and underscored that a positive relationship between them was significant to support the child's process and favour the parent's receptivity and changes, an element that children did not emphasise. Therapists underlined parent's collaboration, and parents highlighted the therapist's commitment and their own with the child's process as change facilitators. Therapists focused more on their flexible, childcentred attitude and interventions as change facilitators. It is noteworthy that when the subjective experience of children and parents is considered, higher importance was given to the affective dimension of the therapeutic relationship as a change facilitator over the focus on technical aspects observed in therapists' views.

In this regard, therapists focused more on the experience of children and parents than on their own. When they addressed their experience, it tended to appear in mixed terms: satisfaction for helping and self-criticism and insecurity for their high emotional involvement with the child's process. Insecurity was more evident in less experienced therapists, as previously reported (Erekson Janis, Bailey, Cattani, \& Pedersen, 2017). However, parents and children in this study positively valued the therapist's high level of commitment; they appreciated it over and beyond the therapist's age or experience, favouring a positive therapeutic relationship and the collaboration of parents and children in therapy. A higher alliance with young therapists was previously reported, but the underlying reasons were not explored (Accurso \& Garland, 2015).

When children and parents' motivation towards therapy improved after the first positive encounters with the therapist, it seemed to support a higher adherence towards therapy, as indicated in previous studies (Hawley \& Weiss, 2005). As these relationships evolved, they opened a space to address personal and interpersonal issues of children and parents that, in the end, improved the parent-child relationship. Accordingly, changes in children and parents also have a positive reciprocal effect. This three-way interconnection has been previously described in terms of the triadic understanding of the therapeutic relationship (Gvion \& Bar, 2014) and the association between children and parents' changes (Alamo, 2019). As noted in this study, when parents establish a positive therapeutic relationship, they become not only open to the therapist intervention and to change but also a vector of the child's change.

\section{Implications for practice}

Children's socio-affective drive towards psychotherapy seems particularly relevant to child psychotherapy. To generate this positive experience for children, child therapists may need to display a close, flexible, and playful attitude and focus on the child's interests and forms of expression such as play or art. Child therapists may feel insecure or guilty when having fun with their patients (Núñez et al., 2021). However, this form of interaction between child and therapist favours the development of the real relationship (Gelso, 2019), which seems central to a positive therapeutic relationship in child psychotherapy (Núñez et al., 2021).

Another implication for practice is that children's initial expectations towards the therapist and the meaning of psychotherapy need to be considered by therapists and parents to favour children's disposition towards psychotherapy. When an initial negative disposition towards the therapist is observed, a therapist willing to adapt to the child's reticence and have fun is vital to improving children's motivation to therapy.

In addition, a positive parent-therapist relationship is central for change to take place and requires special attention. Working with parents may be challenging for child psychotherapists, especially when they display low motivation towards the child's process (Midgley \& Navridi, 2007). However, when the parents seek therapy for their child, they have a more collaborative initial disposition, as was the case in this study. However, this motivation is insufficient and requires developing trust in the parent-therapist relationship to enable a higher disposition for change in parents. The therapist's ability to favour a positive relationship with the child, their direct support to parents and their commitment to the case are essential for parents to advance in this path. 
A final reflection concerns new child therapists' practice. Parents and children appreciated the high commitment displayed by new therapists towards their case. However, this level of involvement also generated selfcriticism in the less experienced therapists. New therapists should recognise the positive influence of their high involvement on the therapeutic relationship and change process. Training should incorporate this element as a central aspect of the therapists' initial experiences.

\section{Strengths and limitations}

A strength of this study was the inclusion of multiple perspectives in exploring a complex phenomenon. Levitt (2021) pointed out that considering multiple perspectives provides an equilibrium concerning power asymmetries. In this study, a higher balance between perspectives was observed in two dimensions: first, the inclusion of children's perspective balanced an adult-centred approach to children's experiences, based on the opinion of parents and therapists, and second, the inclusion of children and parents balanced the professional-centred valuation of the elements that facilitate the child change process. Further studies including multiple perspectives in child and adolescent psychotherapy seem relevant to advance this direction.

The drawings employed in this study supported a deeper exploration of how children viewed themselves, the therapeutic relationship, and their changes. This age-sensitive methodology reinforced children's participation as key informers of their psychotherapy. This study strengthens the notion that children can address their experience through words and drawings, as reported previously (Fernández, 2019; Capella et al., 2015; Nuñez et al., 2021).

A third strength of this study was the collection of data at two different time points, which allowed a broader understanding of the evolving nature of the therapeutic relationship (Horvath, 2006; Roussos, Gómez-Penedo, \& Muiños, 2016). The therapeutic relationship entailed different facilitating functions for change according to the moment of psychotherapy. These results emphasise that the therapeutic relationship in child psychotherapy requires time to develop. In addition, the different trajectories observed between child-therapist and parents-therapist relationships seem relevant for practice and should be explored further.

However, this study presents the limitation that only the initial and middle phases of the therapy were studied and not the later or ending phase. Future studies of the therapeutic relationship until psychotherapy ends may provide a better understanding of children and parents needs for a positive ending of this relationship (Karush, 2014; Núñez et al., 2021). Also, the participants in this study were mostly pleased with how therapy was progressing; this feature is not representative of all children and parents attending therapy services. Exploring the experience of families who drop out of therapy or who have negative experiences of the therapeutic relationship seems necessary to support these processes better.
Another limitation of this study was that most participants were inexperienced therapists. It may be possible that more experienced therapists would have put less emphasis on engaging children through being friendly and would have stressed some of the confrontational aspects of therapy, which new therapists may find harder to implement.

A final limitation was the inability to explore the perspective of fathers or caregivers other than mothers. The lack of fathers' participation may reflect a tendency where mothers assume a more active role in bringing the child to therapy sessions. Regardless, in the understanding that child psychotherapy seems to naturally impact the whole family system, it is essential to include the perspectives of other caregivers besides mothers in future studies.

\section{Conclusions}

The simultaneous analysis of the perspectives of children, parents and therapists in this study enabled a relational comprehension of the change process in child psychotherapy. The child-therapist relationship was viewed as a positive affective experience by participants. Although this relationship did not always start with a collaborative stance in children, the first positive encounters with the therapist facilitated an improved disposition in children. The parent-therapist relationship started from a different point, as parents pursued psychotherapy and were more collaborative from the beginning. As both relationships strengthened, trust in the therapist emerged in children and parents and favoured more profound changes. Children became more emotionally regulated and socially open, and parents expanded their understanding of their problems and how to deal with them. As they both changed, the child-parent relationship improved. At this point of psychotherapy, changes were viewed as significant but insufficient in some children and parents. To achieve deeper change levels, participants considered that the process should continue.

\section{References}

Abrishami, G. F., \& Warren, J. S. (2013). Therapeutic alliance and outcomes in children and adolescents served in a community mental health system. Journal of Child and Adolescent Behavior, 1(2), 1-7. doi:10.4172/2375-4494.1000110.

Accurso, E., \& Garland, A. (2015). Child, caregiver, and therapist perspectives on therapeutic alliance in usual care child psychotherapy. Psychological Assessment, 27(1), 347-352. doi:10.1037/pas0000031.

Alamo, N. (2019). Contenidos y evolución del cambio en la psicoterapia con niños y niñas: Propuesta de un modelo genérico y de proceso [Contents and evolution of change in psychotherapy with boys and girls: Proposal for a generic and process model] [Doctoral dissertation, Pontifical Catholic University of Chile]. Pontifical Catholic University of Chile Repository. Available from: https://repositorio.uc.cl/ handle/11534/22501 
Altimir, C., Capella, C., Núñez, L., Abarzúa, M., \& Krause, M. (2017). Meeting in difference: Revisiting the therapeutic relationship based on patients' and therapists' experiences in several clinical contexts. Journal of Clininical Psychology, 73, 1510-1522. doi:10.1002/jclp.22525.

Anderson, T., Ogles, B. M., Patterson, C. L., Lambert, M. J., \& Vermeersch, D. A. (2009). Therapist effects: Facilitative interpersonal skills as a predictor of therapist success. Journal of Clinical Psychology, 65, 755-768. doi:10.1002/jclp.20583.

Bordin, E. S. (1979). The generalizability of the psychoanalytic concept of the working alliance. Psychotherapy, 16, 252260. doi:10.1037/h0085885.

Campbell, A. F., \& Simmonds, J. G. (2011). Therapist perspectives on the therapeutic alliance with children and adolescents. Counselling Psychology Quarterly, 24(3), 195-209. doi:10.1080/09515070.2011.620734.

Capella, C., Gutiérrez, C., Rodríguez, L. \& Gómez, C. (2018). Change during psychotherapy: the perspective of children and adolescents who have been sexually abused. Research in Psychotherapy: Psychopathology, Process and Outcome, 21(1), 24-39. doi:10.4081/ripppo.2018.288.

Capella, C., Lama, X., Rodríguez, L., Águila, D., Beiza, G., Dussert, D. \& Gutiérrez, C. (2016). Winning a Race: Narratives of Healing and Psychotherapy in Children and Adolescents Who Have Been Sexually Abused. Journal of Child Sexual Abuse, 25(1), 73-92. doi:10.1080/10538712.2015. 1088915.

Capella, C., Rodriguez, L., Aguila, D., Dussert, D., Lama, X., Gutierrez, C. \& Beiza, G. (2015). Storied images of psychotherapeutic change: Approaching children's voices through drawings. Research in Psychotherapy: Psychopathology, Process and Outcome, 18(2), 141-151. doi:10.4081/ripppo.2015.188.

Carlberg, G., Thoren, A., Billstrom, S., \& Odhammar, F. (2009). Children's expectations and experiences of psychodynamic child psychotherapy. Journal of Child Psychotherapy, 35 (2), 175-193. doi:10.1080/00754170902996130.

Carroll, J. (2002). Play therapy: the children's views. Child and Family Social Work, 7(3), 177-187. doi:10.1046/j.13652206.2002.00234.x.

Corbin, J., \& Strauss, A. (2008). Basics of qualitative research: Techniques and procedures for developing grounded theory (3rd ed.). doi:10.4135/9781452230153.

Elliott, R. (2008). Research on client experiences of therapy: Introduction to the special section. Psychotherapy Research 18(3), 239-242. doi:10.1080/10503300802074513.

Erekson, D., Janis, R., Bailey, R., Cattani, K., \& Pedersen, T. (2017). A Longitudinal Investigation of the Impact of Psychotherapist Training: Does Training Improve Client Outcomes? Journal of Counseling Psychology, 64(5), 514-524. doi:10.1037/cou0000252.

Fernández, O., Pérez, C., \& Krause, M. (2016). Therapeutic alliance in the initial phase of psychotherapy with adolescents: different perspectives and their association with therapeutic outcomes. Research in Psychotherapy: Psychopathology, Process and Outcome, 19(1), 1-9. doi:10.4081/ripppo. 2016.180.

Flick, U. (2018). An introduction to qualitative research (6th ed.). Los Angeles: SAGE publications Ltd.

Fonagy, P., Cottrell, D., Phillips, J., Bevington, D., Glaser, D., \& Allison, E. (2015). What Works for Whom? A Critical Review of Treatments for Children and Adolescents (2nd ed.). London: The Guildford Press.
Gelso, C. (2019). The Therapeutic Relationship in Psychotherapy Practice. An Integrative Perspective. New York: Routledge.

Gelso, C. (2014). A tripartite model of the therapeutic relationship: Theory, research, and practice. J. Psychotherapy Research, 24, 117-131. doi:10.1080/10503307.2013.845920.

Gelso, C. J., \& Kline, K. V. (2019). The sister concepts of the working alliance and the real relationship: on their development, rupture, and repair. Research in Psychotherapy: Psychopathology, Process and Outcome, 22(2), 142-149. doi:10.4081/ripppo.2019.373.

Gómez, J.M. \& Roussos, A. (2012). Series on upgrading methodology in clinical psychology. How do we know if our patients are improving? Criteria for clinical significance in psychotherapy: a renewed debate. Revista Argentina de Clínica Psicológica, 21(2), 173-190.

Gonçalves, M., Matos, M. \& Santos, A. (2009). Narrative therapy and the nature of 'innovative moments' in the construction of change. Journal of Constructivist Psychology, 22(1), 1-23. doi:10.1080/10720530802500748.

Green, J. (2006). Annotation: The therapeutic alliance - a significant but neglected variable in child mental health treatment studies. Journal of Child Psychology and Psychiatry, 47(5), 425-435. doi:10.1111/j.1469-7610.2005.01516.x.

Gvion, Y., \& Bar, N. (2014). Sliding doors: some reflections on the parent-child-therapist triangle in parent work-child psychotherapy. Journal of Child Psychotherapy, 40(1), 58-72. doi:10.1080/0075417X.2014.883138.

Hawley, K. M., \& Weisz, J. R. (2005). Youth versus parent working alliance in usual clinical care: Distinctive associations with retention, satisfaction, and treatment outcome. Journal of Clinical Child and Adolescent Psychology, 34(1), 117128. doi:10.1207/s15374424jccp3401_11.

Horvath, A. O. (2006). The alliance in context: Accomplishments, challenges, and future directions. Psychotherapy: Theory, Research, Practice, Training, 43(3), 258-263. doi:10.1037/0033-3204.43.3.258.

Horvath, A., Del Re, A. C., Flükiger, C., \& Symonds, D. (2011). Alliance in Individual Therapy. In Norcross, J. (Ed.), Therapeutic relationships that work: Evidence-Based Responsiveness (pp. 25-69). New York: Oxford University Press.

Karush, R. (2014). Postscripts: Reflections on the post-termination phase. The Psychoanalytic Study of the Child, 68, 234247. doi:10.1080/00797308.2015.11785516.

Karver, M. S., Monahan, M., De Nadai, A. S., \& Shirk, S. R. (2018). Meta-Analysis of the Prospective Relation Between Alliance and Outcome in Child and Adolescent Psychotherapy. Psychotherapy, 55(4), 341-355. doi:10.1037/pst0000176.

Kazdin A. E., \& Durbin, K. A. (2012). Predictors of child-therapist alliance in cognitive- behavioral treatment of children referred for oppositional and antisocial behavior. Psychotherapy (Chic., III) 49(2), 202-217. doi:10.1037/a0027933.

Kazdin, A. E., Whitley, M., \& Marciano, P. L. (2006). Child-therapist and parent-therapist alliance and therapeutic change in a treatment referred for oppositional, aggressive, and antisocial behaviour. Journal of Child Psychology and Psychiatry, 47(5), 436-445. doi:10.1111/j.1469-7610.2005.01475.x.

Krause, M., de la Parra, G., Arístegui, R., Dagnino, P., Tomicic, A., Valdés, N., Vilches, O., Echávarri, O., Ben Dov, P., Reyes, L., Altimir, C., \& Ramírez, I. (2006). Indicadores genéricos de cambio en el proceso psicoterapéutico. Revista Latinoamericana de Psicología, 38(2), 299-325.

Krause, M. (2005). Psicoterapia y cambio. Una mirada desde la subjetividad [Psychotherapy and change. A view from 
subjectivity]. Santiago de Chile: Ediciones Universidad Católica.

Levitt, H. (2021). Essentials of Critical-Constructivist Grounded Theory Research. Washington, DC: American Psychological Association.

Liber, J., McLeod, B., Van Widenfelt, B., Goedhart, A., Van der Leeden, A., Utens, E., \& Treffers, P. (2010). Examining the relation between the therapeutic alliance, treatment adherence, and outcome of cognitive behavioral therapy for children with anxiety disorders. Behavior Therapy, 41(2), 172-186. doi:10.1016/j.beth.2009.02.003.

Marker, C., Comer, J., Abramova, V., \& Kendall, P. (2013). The reciprocal relationship between alliance and symptom improvement across treatment of childhood anxiety. Journal of Clinical Child \& Adolescent Psychology, 42(1), 22-33. doi:10.1080/15374416.2012.723261.

Mergenthaler, E., \& Gril, S. (1996). Descripción de las reglas para la transcripción de sesiones de psicoterapia [Description of the rules for the transcription of psychotherapy sessions]. Revista Argentina de Clínica Psicológica 5(2), 163-176.

Midgley, N. (2004). Sailing between Scylla and Charybdis: Incorporating qualitative approaches into child psychotherapy research. Journal of Child Psychotherapy, 30(1), 89-111. doi:10.1080/0075417042000205814.

Midgley, N., Hayes, J., \& Cooper, M. (2017). Essential research findings in child and adolescent counselling and psychotherapy. London: SAGE publications Ltd.

Midgley, N. \& Navridi, E. (2006) An exploratory study of premature termination in child analysis. Journal of Infant, Child and Adolescent Psychotherapy, 5(4), 437-58. doi:10.1080/1 5289160701382360.

Noyce, R., \& Simpson, J. (2018). The experience of forming a therapeutic relationship from the client's perspective. Psychotherapy Research, 28(2), 281-296. doi:10.1080/ 10503307.2016.1208373.

Núñez, L., Midgley, N., Capella, C., Alamo, N., Mortimer, R. \& Krause, M. (2021). The therapeutic relationship in child psychotherapy: integrating the perspectives of children, parents and therapists. Psychotherapy Research, 31(8), 988-1000. doi:10.1080/10503307.2021.1876946.

Papalia D. E., \& Martorell, G. (2015). Experience Human Development (13th ed.). McGraw-Hill Education.
Principe, J. M., Marci, C. D., Glick, D. M., \& Ablon, J. S. (2006). The relationship among patient contemplation, early alliance, and continuation in psychotherapy. Psychotherapy: Theory, Research, Practice, Training, 43(2), 238. doi:10.1037/ 0033-3204.43.2.238.

Roussos, A. J., Gómez-Penedo, J. M. y Muiños, R. (2016). A time-series analysis of therapeutic alliance, interventions, and client's clinical status in an evidence-based single-case study: Evidence for establishing change mechanisms in psychotherapy. Psychotherapy Research. doi:10.1080/ 10503307.2016.1174346.

Shirk, S. R., \& Karver, M. S. (2011). Alliance in child and adolescent psychotherapy. In Norcross, J. (Ed.), Therapeutic relationships that work: Evidence-Based Responsiveness (pp. 70-91). New York: Oxford University Press.

Shirk, S. R., \& Karver, M. (2003). Prediction of treatment outcome from relationship variables in child and adolescent therapy: a meta-analytic review. Journal of Consulting and Clinical Psychology, 71(3), 452. doi:10.1037/0022- 006X. 71.3.452.

Titscher, M., Meyer, M., Wodak, R., \& Vetter, E. (2000). Methods of Text and Discourse Analysis: In Search of Meaning. London: SAGE Publications Ltd.

Weisz, J., Yi Ng, M., Rutt, C., Lau, N. \& Masland, S. (2013). Psychotherapy for children and adolescents. In M.J. Lambert (Ed.), Bergin and Garfield's handbook of psychotherapy and behavior change (5th ed., pp. 541-586). New York: John Wiley \& Sons.

Wilmots, E., Midgley, N., Thackeray, L., Reynolds, S., \& Loades, M. (2019). The therapeutic relationship in Cognitive Behaviour Therapy with depressed adolescents: A qualitative study of good-outcome cases. Psychology and Psychotherapy: Theory, Research and Practice, 93(2), 1-16. doi:10.1111/papt.12232.

Zandberg, L. J., Skriner, L. C., \& Chu, B. C. (2015). Client-therapist alliance discrepancies and outcome in cognitive-behavioral therapy for youth anxiety. Journal Clinical Psychology, 71(4), 313-322. doi:10.1002/jclp.22167.

Zorzella, K., Rependa, S., Muller. R. (2017). Therapeutic alliance over the course of child trauma therapy from three different perspectives. Child Abuse \& Neglect, 67, 147-156. doi:10.1016/j.chiabu.2017.02.032. 